\title{
ACERCA DE LA INVESTIGACIÓN DEL ARTE PLUMARIO COLONIAL DE SUDAMÉRICA. POSIBILIDADES Y PERSPECTIVAS DE LA CULTURA VISUAL HISTÓRICA EN UN CONTEXTO INTERCULTURAL
}

\author{
ABOUT THE INVESTIGATION OF COLONIAL FEATHER ART FROM \\ SOUTH AMERICA. POSIBILITIES AND PROSPECTS OF \\ THE HISTORICAL VISUAL CULTURE IN AN INTERCULTURAL CONTEXT
}

\author{
Friederike Berlekamp*
}

\begin{abstract}
Solamente pocos mosaicos plumarios de la época colonial de Sudamérica son conocidos. En las colecciones del Museo de América en Madrid y del Museo Nacional de Colombia en Bogotá existen en total 11 piezas, provenientes del Perú, respectivamente de la zona andino-amazónica y datadas en los siglos XVII/XVIII. Ninguna de estas tiene una documentación completa, pero a pesar de todo, estos mosaicos pueden servir como fuentes gráficas históricas. Análisis materiales, técnicas e iconográficas, comparaciones con otros objetos plumarios y con otras hechuras artísticas y la lectura de fuentes escritas contemporáneas facilitan sus contextualizaciones en misiones jesuíticas. Por la combinación de los problemas de la cultura visual con los de las investigaciones de transferencias culturales es posible circunstanciar este contexto de su creación: encuentros entre personas de raíces culturales distintas en los siglos XVII/XVIII en Sudamérica.
\end{abstract}

Palabras claves: Arte plumario, misiones jesuíticas, encuentros interculturales, transferencias culturales.

\begin{abstract}
Only few feather mosaics from the colonial time from South America are known. In the collections of the Museo de América in Madrid and the Museo Nacional de Colombia in Bogota exists a total of 11 pieces which are located in Peru and in the Andean zone respectively and dated in the 17th/18th century. None of these objects is documented, but notwithstanding this they can serve as graphic historical sources. Material, technical and iconographic analyses, comparisons with other feather objects and works of art, and the reading of contemporary written sources enable their contextualizations in Jesuits' missions. By the combination of the problems of the Historical Visual Culture with those of the research of cultural transfer it is possible to explain the context of their creation in detail: encounters between persons with different cultural backgrounds in the 17th/18th century in South America.

Key words: Feather art, Jesuits' mission, intercultural encounters, cultural transfer.
\end{abstract}

\section{Introducción}

Mosaicos plumarios de Sudamérica de la época colonial son representantes de un arte muy poco conocido y apenas investigado. Se trata de objetos planos diseñados, cuyas representaciones gráficas están realizadas con plumas completamente a manera de mosaicos. Hasta ahora pocas imágenes de plumas son conocidas; para este estudio solamente 11 piezas estuvieron a disposición. Se trata de tres tapices, un frontal de altar, tres tiras grandes y cuatro piezas decorativas pequeñas. Diez mosaicos pertenecen a la colección del Museo de América en Madrid; un tapiz se ubica en el Museo Nacional de Colombia en Bogotá (1). Los ejemplares madrileños provienen del Perú, respectivamente de la zona andino-amazónica y están datadas entre 1650 y 1800 (Museo de América s.a.). El origen del tapiz bogotano se localiza en Perú, aún no se conoce su fecha (Museo Nacional de Colombia 2013). Sobre la procedencia y la historia de estas imágenes no existe ninguna documentación.

En estudios previos de estos mosaicos plumarios apenas se les habían considerado como fuentes gráficas históricas. Pero de tal comprensión y a base de análisis materiales, técnicos e iconográficos pueden surgir indicaciones para interpretaciones contextuales y por tanto historiográficas. Las preguntas de interés etnohistórico dirigidas a las piezas conciernen por ejemplo a las razones y circunstancias de su creación y fabricación, a sus percepciones y efectos contemporáneos y especialmente a los protagonistas

* Investigadora independiente. Berlín, Alemania. Correo electrónico: r.adelbert-w@ posteo.de 
y a sus contribuciones al proyecto, a la confección y al empleo de tales hechuras.

La información escrita coetánea sobre objetos de plumas es muy dispersa y apenas concreta, así que la investigación del arte plumario de la época colonial queda aún difícil. Empero, ya las características de los mosaicos dan indicios importantes, demostrando influencias de tradiciones tanto indígenas como europeas. En consecuencia, como las imágenes reflejan un origen intercultural, estas pueden servir como documentos de encuentros entre representantes de distintas culturas.

La lectura de fuentes escritas de los siglos XVII/ XVIII permite la contextualización más concreta de este contacto: con alta probabilidad las piezas proceden de las misiones jesuíticas. Reflexiones sobre la confección y el empleo de los mosaicos afirman esta interpretación. En este escenario los misioneros figuraban seguramente como los iniciadores de la elaboración de las obras de plumas, los indígenas eran los destinatarios principales y aportaban a la fabricación.

Concentrándose en las funciones, los efectos y significados del arte plumario se puede circunstanciar el contexto reconstruido. La cultura visual facilita el acercamiento. Se subraya la potencia comunicativa y creativa de objetos diseñados, dando atención especial sobre las interacciones entre imágenes y protagonistas y también entre obras y el entorno (Bredekamp 2010:52; Paul 2012:s.p.). De suma importancia aquí es la percepción -un aspecto central de la cultura visual-. Sin embargo, su consideración no puede fijarse meramente en la captación de los mosaicos durante su contemplación, sino tiene que incluir además la atención a todos los actos y actuaciones vinculados con las piezas y también la apreciación mutua de los partícipes. Como las interacciones y comunicaciones por medio de las imágenes de plumas -a partir de su proyección y fabricación hasta su empleo y contemplación- no suceden simultáneamente, percepciones ambiguas son posibles e inevitables (Kemp 2003:251).

Aparte de los problemas de la cultura visual las características materiales, técnicas e iconográficas de los mosaicos dan indicaciones de suma importancia para la interpretación de la situación de su creación. Tanto tradiciones indígenas del arte plumario como tradiciones artísticas europeas son perceptibles, en consecuencia, los mosaicos reflejan contactos entre protagonistas de raíces culturales distintas. El origen y la datación señalados de las piezas -en el (virreinato del) Perú/en la zona andina y en los siglos XVII/XVIII- lo afirman. Este contexto colonial $-\mathrm{y}$ en particular con la concreción en las misiones jesuíticas- era caracterizado por encuentros interculturales, por la introducción de un nuevo sistema cultural y, en consecuencia, por amplios (inter)cambios culturales.

A causa de este escenario histórico es preciso agrandar la perspectiva del estudio. Incluir también problemas de las investigaciones de transferencias culturales permite subrayar el carácter transcultural de las hechuras y las particularidades de su procedencia. Además, las investigaciones de transferencias culturales se dedican también a la investigación de interacciones: se concentran en contactos intra e interculturales, en los desarrollos de captaciones y reflexiones, las causalidades de transferencias y los tipos de transmisiones (Gerogiorgakis et al. 2011:s.p.). Con esta perspectiva las imágenes plumarias proporcionan información más dilatada, interrogándolas como productos de encuentros interculturales, medios de comunicación y vehículos de intercambios culturales. La consideración de la percepción-tanto de los mosaicos como también de los protagonistas y de los actos- se vuelve así aún más compleja, porque las apreciaciones cambian durante los procesos y, además, varían mucho en correspondencia con los sistemas de referencia específicos (Schulz 2005:73).

Entonces, esta combinación de los problemas de la cultura visual con los de las investigaciones de transferencias culturales puede llevar a explicaciones amplias de las obras de plumas coloniales y de la situación de su creación. Aparte de esto se adquieren conocimientos acerca de encuentros interculturales en Sudamérica durante la época colonial.

Este estudio de las imágenes plumarias coloniales de Sudamérica es un intento de una interpretación contextual, basado en análisis profundos, comparaciones técnicas, iconográficas y estilísticas y en la lectura de fuentes escritas contemporáneas.

\section{Los Mosaicos y las Tradiciones del Arte Plumario}

El corpus de estos 11 mosaicos de plumas consiste en representantes de dos tipos técnicos diferentes. Una de estas técnicas se caracteriza por hileras de plumas anudadas (Figura 1). Estas hileras están cosidas en filas horizontales encima de telas de algodón (Mercedes Amezada Ramos, 


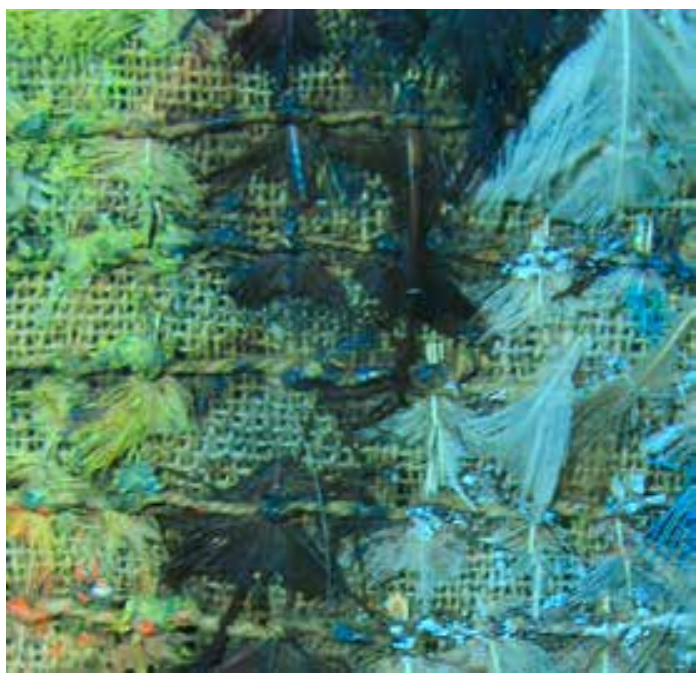

Figura 1. Detalle del tapiz (número de inventario: 12344, Museo de América).

comunicación personal 2009, 2011). Los estandartes se orientan hacia abajo y hacia afuera. Seis de los objetos pertenecen a este tipo (2). La hechura de las otras cinco piezas (3) se califica por plumas insertadas en un tejido mezclado de material lignificado y algodón (Figura 2) (Artelan Restauración S.L. 2007; Carmen González de Candamo, Dolores Medina Bleda y Mercedes Amezada Ramos, comunicación personal 2009) (4). Los estandartes aquí muestran hacia arriba o hacia la izquierda. En los dos grupos los estandartes de las plumas solapan, de modo que cubren o mejor dicho cubrían todos los soportes completamente, construyendo así -a la manera de mosaicos- las representaciones gráficas (5).

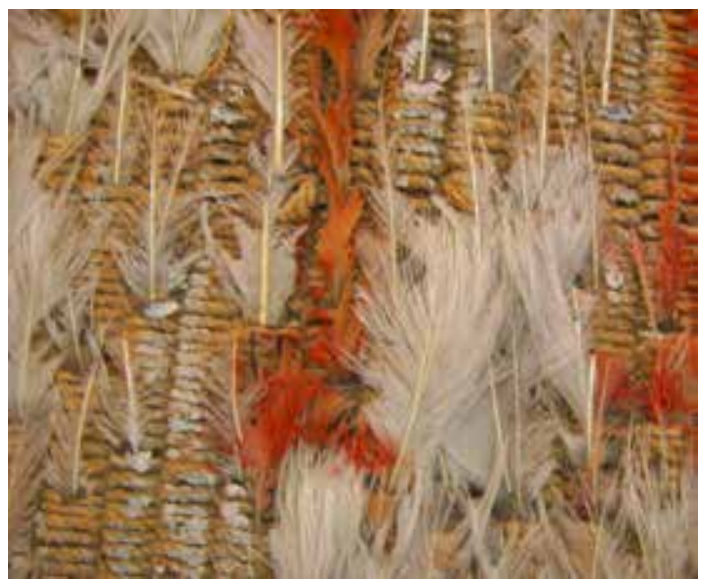

Figura 2. Detalle del frontal de altar (número de inventario: 12346, Museo de América).
El arte plumario es una tradición extendida, remota y muy variada en todas las Américas. Hay por tanto varios testimonios arqueológicos y etnográficos -como por ejemplo tocados, ropa, adornos corporales, bastones, rodelas o colgaduras- como también pruebas escritas. La documentación de obras sudamericanas plumarias y de su empleo abarca material desde tiempos muy remotos, desde aproximadamente 3.500 a.n.e. en la costa peruana (Grieder et al. 1988:75), hasta hoy en muchas regiones (cf. Escobar 1993; Gisbert et al. 2003:81; Kästner 2009).

No obstante, la comparación técnica de los mosaicos de la época colonial con otros objetos plumarios de formas tradicionales de Sudamérica muestra que no se pueden relacionar estas piezas con tradiciones indígenas directamente. Las imágenes de plumas anudadas recuerdan a prácticas precolombinas conocidas de la zona costal del Perú y de la zona andina. Empero, aquellas están caracterizadas por particularidades técnicas y acabados de calidad inferior. En cambio, en cuanto a los mosaicos de plumas insertadas, ningún ejemplar comparable estuvo disponible para este estudio. Hechuras de tejidos mezclados son extendidas y conocidas, pero no fue posible encontrar objetos con decoraciones completas de plumas. Sin embargo, en fuentes escritas contemporáneas se mencionan tales fabricaciones con decoraciones de plumas, de vez en cuando son figurativas (Cobo 1956:II:254 [ca. 1653]; Orellana 1704:s.p.; Altamirano 1891:107, 109/110 [1715]; Eder 1888:158 [1791]).

De creaciones plumarias europeas casi no existen pruebas hasta la Edad Media tardía (Dought 1975:6), pero sí existían largas tradiciones de elaborar y emplear adornos de plumas en varias regiones de Europa. Estas prácticas evolucionaron hasta los siglos XVII/XVIII, naciendo la ocupación artística con plumas y el oficio del plumassier, quien trabajaba adornos de cascos o de sombreros, adornos de caballos y vestidos de teatros (Marperger 1717:272, 279, 304; Diderot 1754-1772:XII:800; Doughty 1975:1; MacLean 2006:s.p.). Probablemente, de vez en cuando estas hechuras estaban inspiradas por medio de informes escritos sobre el Nuevo Mundo y asimismo por medio de objetos e indígenas traídos a partir del final del siglo XV desde América hacia Europa. Por consiguiente, las prácticas europeas se enriquecieron por los conocimientos nuevos en correspondencia con 
propias ideas, experiencias y exigencias, dando a luz confecciones particulares, pero sin alcanzar apenas la calidad de mosaicos. Un ejemplo del arte plumario europeo excepcional y de alta complejidad se encuentra en el castillo de Moritzburg en Sajonia, Alemania. Es un conjunto de tejidos plumarios fechado en el siglo XVIII. Se trata de decoraciones de una habitación, adornando la cama con dosel y las paredes. La técnica y el acabado son muy elaborados. Las imágenes están realizadas completamente con plumas anudadas a hileras y entretejidas a manera de tapiz (Hofmann y Tradler 2003:36). Es un procedimiento que recuerda a hechuras mexicanas.

La iconografía de las piezas presentadas aquí se orienta en tradiciones europeas. No solo algunos motivos -como el monograma de Cristo, leones, águilas bicéfalas coronadas y flores y jarrones-, sino igualmente motivos decorativos, el empleo consciente de colores simbólicos y de formas compositoras y el estilo reflejan esta influencia. En cambio, la iconografía del arte plumario indígena se caracteriza más bien por diseños colorados o geométricos. A menudo son no figurativos, pero se encuentran también -sobre todo en objetos precolombinos- representaciones estilizadas de animales, seres míticos/fantásticos y tal vez de seres humanos. Estas creaciones son más bien repetitivas o simétricas. Los colores son ricos en contrastes y en matices.

Es difícil de clasificar los contenidos de las obras plumarias de la época colonial. Solamente una pieza tiene una iconografía inequívoca. Es el frontal del altar, que muestra claramente un tema cristiano (Figura 3).

Pero considerando las tradiciones tanto europeas como también indígenas la diferencia entre los sistemas de referencia de los partícipes y además los varios niveles significativos de imágenes, las representaciones pueden llevar más bien a captaciones e interpretaciones ambiguas.

Aun cuando no se puede relacionar los mosaicos de la época colonial ni por medio de la técnica ni por medio de la iconografía con tradiciones indígenas directamente, sin duda estas formaban una condición básica para la elaboración de estos objetos. Otra circunstancia consistía en el interés en seguir con la fabricación y el empleo de tales hechuras bajo una influencia muy marcada de las prácticas y de la moda europeas.

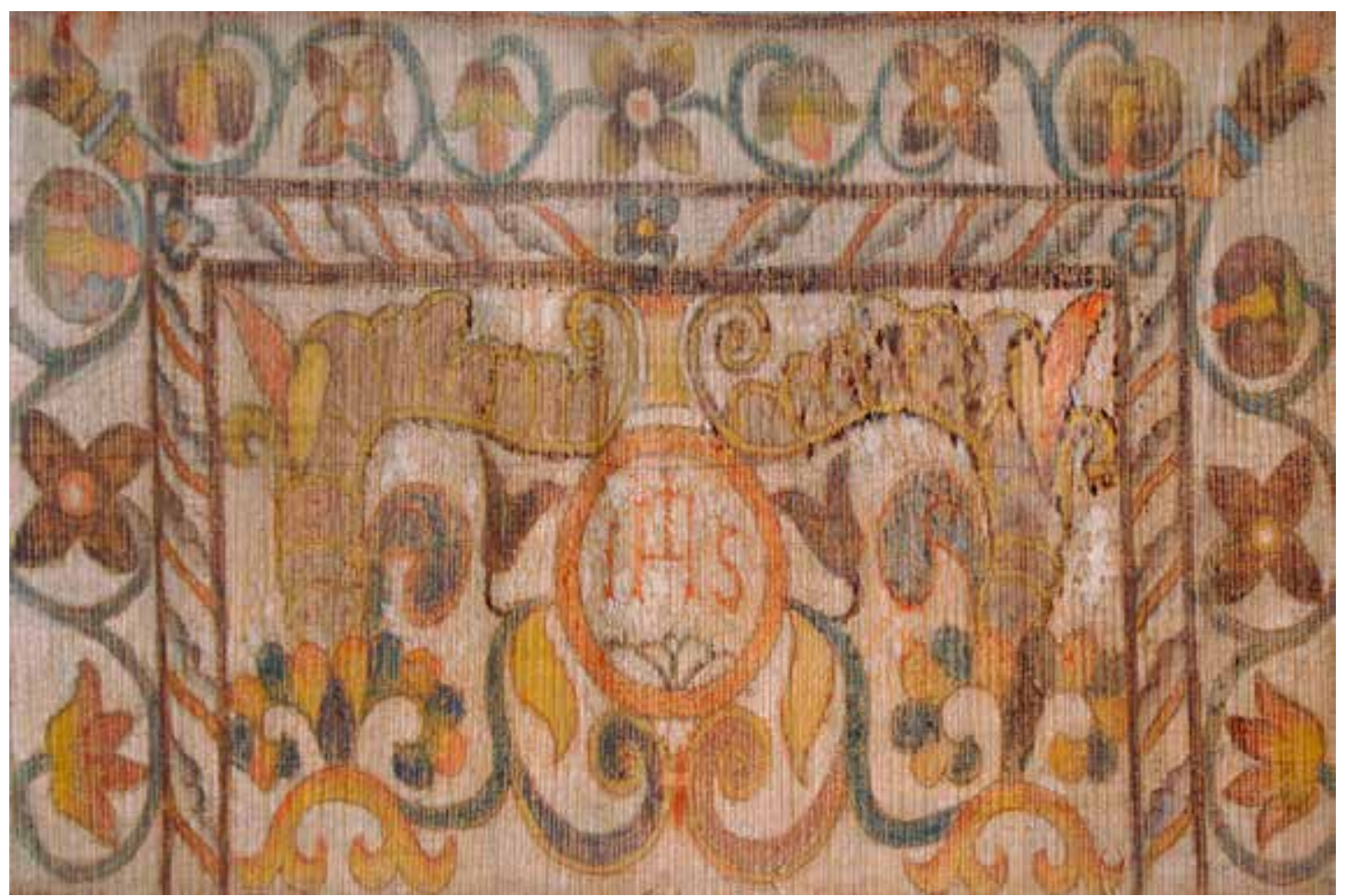

Figura 3. Frontal de altar, foto: Museo de América, Madrid. 


\section{Ambigüedades de los Mosaicos Plumarios}

Si bien las imágenes plumarias demuestran claramente un carácter europeo, no es suficiente en este estudio dedicarse a la iconografía, considerando solamente el canon artístico europeo. En el escenario planteado, que era caracterizado por encuentros interculturales, estas obras estaban contempladas por personas de distintas raíces culturales y, en consecuencia, estaban caracterizadas por distintos sistemas de referencia. La atención se dirige entonces a las percepciones posibles de las representaciones desde las perspectivas diversas de los protagonistas tanto indígenas como europeos. Igualmente, es preciso reflexionar respecto de las concepciones distintas de los partícipes acerca de imágenes u objetos. En el caso del arte plumario también el material usado -las plumas y su empleo- es de interés especial.

Contemplando los mosaicos, el carácter de costumbres decorativas y visuales europeas es reconocible: en la elección de los motivos, en los acabados estilísticos y asimismo en las composiciones. Pero ya motivos sueltos aclaran que las apreciaciones de los significados simbólicos podían ser varias y distintas. Un ejemplo explicativo da uno de los tapices (Figura 4).

En esta imagen se ven muchos pájaros, entre ellos un guacamayo macao (Ara macao), un pavo carunculado (Crax globulosa), un tucán toco (Ramphastos toco) y tal vez una paloma aliblanca (Patagioenas corensis), una amazona frentiazul (Amazona aestiva) y un gallito de las rocas guayanés (Rupicola rupicola). Son todos pájaros sudamericanos, y son todos de importancia simbólica para varios grupos indígenas. Los testimonios sudamericanos indican que las significaciones son diversas. Reflexiones atinentes a la apariencia del guacamayo, situado en el centro de la representación, lo explicarán. Desde el periodo intermedio temprano (200 a.n.e.- 600) la utilización de sus plumas ya está documentada en la costa peruana (Yacovleff 1933:140). Y a partir de la misma época hay igualmente pruebas arqueológicas de efigies del guacamayo, muchas veces del aspecto del pájaro rojo. La sustancia simbólica de estas aves es aún desconocida. Los informes escritos de la época colonial de los inkas dan información más explicativa, pero sin aclarar el fundamento de este símbolo tampoco. En las fuentes se relata de la estimación de estos pájaros por los inkas y especialmente por las coyas como objeto de prestigio y lujo (Murúa 2004:fol. 28v/29r
[1590]; Garcilaso de la Vega 2002:fol. 105v [1609]; Guamán Poma de Ayala 2001:132/133, 142, 334 [1615]). Este aprecio se basó probablemente en su color rojo, su origen en el este de las cordilleras -en regiones lejas, desconocidas y míticas- y en su facilidad de volar en alturas extremas, posibilitando así imaginaciones relacionadas con el sol. Además, en varias leyendas amazónicas el guacamayo figura como el progenitor mítico o el héroe cultural (Molina 2008:14/15 [1575]; Cobo 1956:II:152 [ca. 1653]; Techo 1897:II:313 [1673]). De la época colonial existen todavía objetos demostrando su importancia simbólica, como por ejemplo los kerus y los retratos de inkas y sobre todo de coyas y ñustas, en donde un guacamayo aparece como atributo. Asimismo, los nombres de ciertos grupos indígenas antiguos y modernos indican la trascendencia de los guacamayos, usando su nombre para la denominación del propio o del otro grupo (Sánchez Labrador 1769-1776:fol. 138r, Kästner 2009:100, 104, 156). Y aún hoy para muchos grupos sudamericanos estos pájaros están relacionados con el sol y sus rayos (Furst 1991:94; Escobar 1993:139).

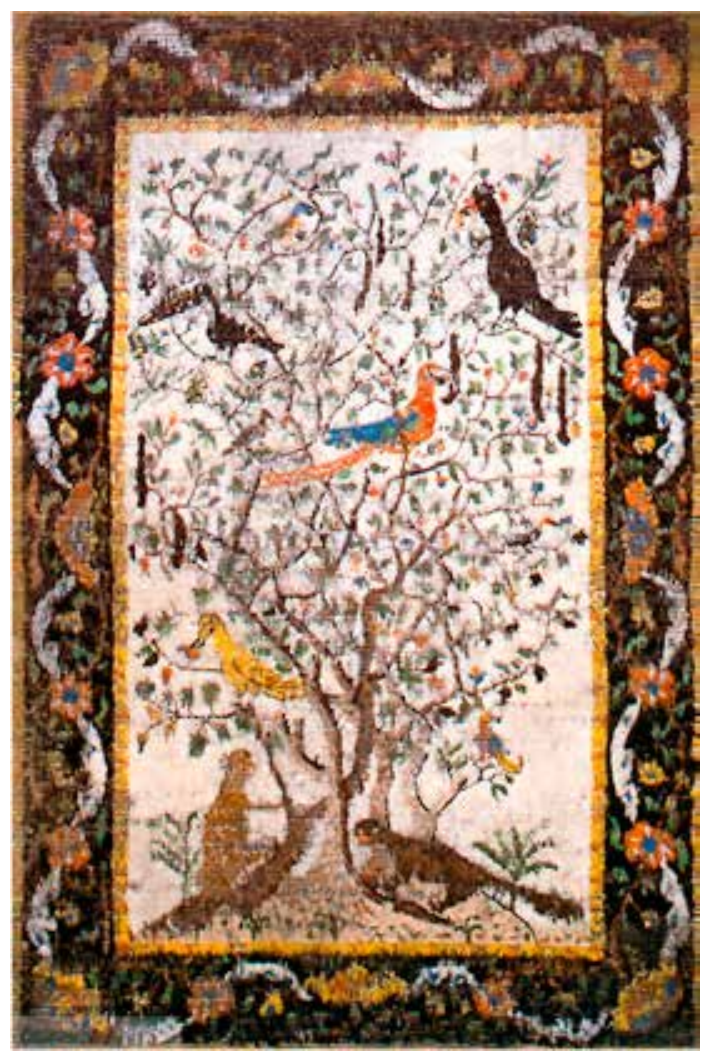

Figura 4. Tapiz, foto: Museo de América, Madrid. 
A diferencia, en el arte europeo se encuentran pocos pájaros sudamericanos, apareciendo sobre todo en ilustraciones científicas o cuadros enciclopédicos. Solamente los loros y especialmente los guacamayos entraron en el canon simbólico europeo. Ellos son un motivo muy ambiguo; representan a sentimiento, placer y necedad y también a facilidad de comprensión. Y como símbolo cristiano refieren a Eva y a la Virgen María (Heinz-Mohr 1981:230; S. Dittrich y L. Dittrich 2004:322/323).

Este tapiz muestra una reunión de aves sudamericanas en un árbol. Esta representación puede remitir a cosmovisiones indígenas y reflejar el orden étnico, social, etc. A la vez es posible entenderla como una reproducción de la naturaleza y avifauna exóticas de Sudamérica o como alusión a sujetos bíblicos, al paraíso pasado y futuro, incluyendo el mundo americano en las ideas cristianas.

El material usado -las plumas-diversifica la percepción de los mosaicos encima. Mientras para los europeos de aquella época las plumas eran un elemento sobre todo útil, pero a la vez decorativo, para muchos grupos indígenas eran uno de sus medios de comunicación principales, usándolas en momentos de importancia. Por ejemplo, especialmente mediante tocados plumarios expresan su identidad tanto individual como del grupo. De esta manera manifiestan sus propias capacidades o las de su alter ego y así declaran su posición en el ambiente real y en el mundo espiritual (Furst 1991:94; Escobar 1993:130/131, 133).

El carácter particular de sistemas de referencias conciernen igualmente a las ideas de imágenes y objetos, afectando considerablemente a sus captaciones y entendimiento. Por tanto, las significaciones atribuidas están definidas por estas conceptuaciones. En la Europa de la Antigüedad había surgido un cambio de la concepción de imágenes desde una noción culto-mágica hacia un concepto de representar (Sachs-Hombach 2003:s.p.). En consecuencia, para los europeos de los siglos XVII y XVIII obras artísticas remitían al significado simbólico. En cambio, los indígenas tenían una idea culto-mágica. Para ellos las hechuras no solamente materializan lo alusivo y lo no representable, sino ellas mismas lo encarnan.

Por estas diferencias de conceptuación, surgiendo a varios niveles, la fabricación y el empleo de los mosaicos de la época colonial conducen a apreciaciones muy ambiguas en el contexto de encuentros interculturales. Para los indígenas la información simbólica del arte plumario era perceptible por vías múltiples: por medio de las representaciones, del material usado (y también de la técnica empleada), del objeto, de las circunstancias y de la utilización apropiadora. Al contrario, para los europeos el mensaje se llegaba a saber contemplando la imagen y el contexto del uso.

\section{Los Mosaicos como Medios de Comunicación y Vehículos de Intercambio}

Después de mostrar la complejidad de las categorías significativas del arte plumario y explicar las posibilidades de percepciones de los mosaicos, surgiendo de las nociones particulares, quedan pendientes las preguntas por los significados y funcionamientos de las imágenes de plumas como medios de comunicación y como vehículos de intercambio dentro del escenario misionero.

En este contexto la atención no puede limitarse en el momento de la contemplación de las obras solamente, porque los procesos comunicativos e interactivos empezaron ya en la fase de la inspiración de los iniciadores, induciéndoles a la confección de mosaicos con decoraciones de índole europeo y de vez en cuando también cristianas, usando plumas como material de representación. Esta adopción por los sacerdotes se basa principalmente en las consideraciones siguientes. Las fuentes escritas documentan que los misioneros admiraban la hermosura de objetos plumarios y la destreza de los artistas indígenas (Salinas Loyola 1965:201 [1571]; Saabedra 1965:247 [1620]; Fernández 1895:II:73 [1726]; Eder 1888:146, 158 [1791]). Creando imágenes de plumas ellos aprovecharon los conocimientos y facilidades de los indígenas y asimismo los recursos disponibles. Este pensamiento tuvo también un origen económico. Debido al gran aislamiento de las poblaciones misioneras y por la autarquía necesaria o pretendida los clérigos tuvieron que recurrir a las posibilidades locales para desarrollar sus aldeas. Otra consideración concierne a la gran significación y valoración de objetos plumarios por los indígenas, que los misioneros habían reconocido. Por esto y en correspondencia con su práctica de acomodación los evangelizadores quisieron tomar esta tradición indígena de adornar a personas y objetos con plumas en momentos especiales, empleándola para la introducción y el desarrollo de su propio sistema religioso con sus eventos litúrgicos. Esta adopción de una práctica 
indígena les serviría para facilitar a los neófitos el acceso a este nuevo sistema de la misión. La confección y el uso de mosaicos plumarios les valieron por partida doble: los padres pudieron aplicar el empleo y la exhibición de las imágenes en las ceremonias como medios de la catequesis visual, explicando conceptos europeos y cristianos. La fabricación por los artistas indígenas mismos les sirvieron igualmente para la catequesis vivida; de esta manera los indígenas participaron activamente en la realización de la vida cristiana en la tierra.

Ahora bien, reconstruida la comunicación intencionada e idealizada mediante hechuras plumarias -la promoción de la cultura europea y cristiana-, hay que preguntarse por los desarrollos posibles de este intercambio, dirigiendo la atención a los indígenas como destinatarios de las obras y, aún más, como protagonistas en los encuentros interculturales.

El corpus refleja dos escenarios distintos: tanto la técnica como también las iconografías de los mosaicos de plumas insertadas indican una participación directa de indígenas y de europeos. A causa de los acabados técnicos y por diferencias entre el diseño y la realización se puede reconocer tanto habilidades, conocimientos y libertades artísticos y artesanales como de vez en cuando también desconocimientos y faltas de comprensión. Un ejemplo lo da el frontal del altar, mostrando un emblema con el monograma de Cristo, pero con el elemento importante de los tres clavos modificado en una flor (Figura 5).

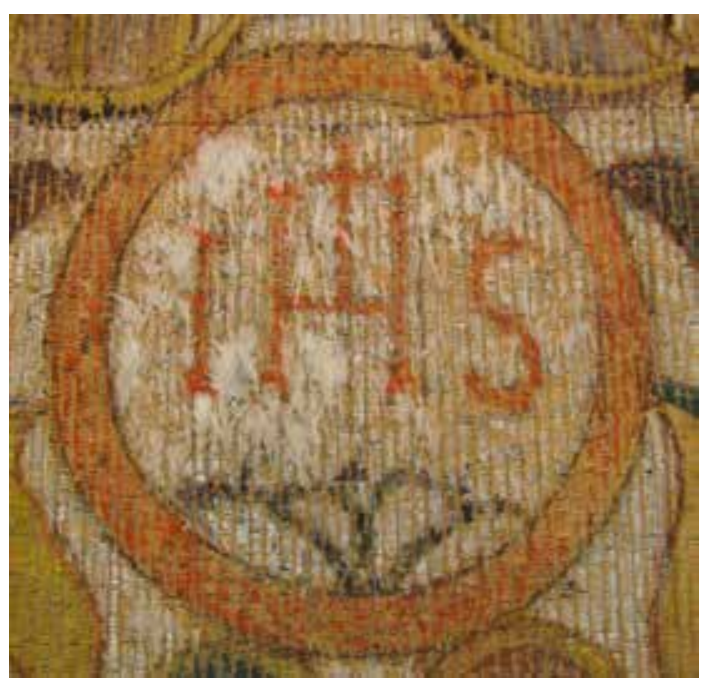

Figura 5. Detalle del frontal de altar.
Las piezas de este grupo atestiguan cierta cooperación, posiblemente caracterizada por obstáculos. Pensando en la participación activa y amplia de los artistas indígenas de plumas, esta colaboración aparece sin embargo quebradiza. De hecho, con alta probabilidad sin consciencia de los iniciadores, los artistas indígenas recibieron un papel crucial en esta comunicación por medio de imágenes plumarias. Trabajando plumas tradicionalmente, ellos eran los comunicadores con el mundo espiritual: con las deidades, espíritus protectores, héroes culturales y con los antepasados reales o míticos; probablemente tenían capacidades chamanísticas y conocimientos amplios acerca del pasado, el presente y el futuro. Por esto, estas personas eran apreciadas en alta estima y jugaban un papel central en el sistema ritual, social y político de los grupos indígenas. Siguiendo el empleo de las plumas en el nuevo sistema misional, ellos pudieron continuar la comunicación mediante el arte plumario con sus propios signos. De esta manera ofreciendo a los indígenas una oportunidad de propios intercambios intelectuales, los artistas de plumas pudieron encargarse como emisores de mensajes, de modo que mantuvieron su rol y su posición tradicional en su grupo. Por consiguiente, desplazaron a los misioneros como emisores originales e impidieron su integración en esta comunicación a la vez.

En cambio, en las piezas de plumas cosidas la participación activa de indígenas es menos perceptible, ni en la técnica usada ni en los acabados gráficos. Pero la hechura da las siguientes indicaciones para interpretaciones de este grupo. El procedimiento recuerda tradiciones indígenas. Hileras de plumas fueron cosidas encima de telas. Sin embargo, la comparación demuestra claramente que ni se empleó una técnica tradicional ni la perfeccionaron. $\mathrm{La}$ utilización gruesa de pegamiento y la negligencia en el tratamiento de las plumas demuestran más bien que estas imágenes fueron fabricadas en un contexto en el que no se tenía la tradición de elaborar objetos plumarios con hileras de plumas. De estas particularidades se puede deducir además que las obras fueron confeccionadas por personas que no comprendían la concepción indígena de plumas y la trascendencia de su elaboración y empleo. Las piezas de este grupo representan más bien una nueva creación del arte plumario de formas, contenidos y significaciones nuevos. En el escenario misionero se puede identificar con alta probabilidad el clérigo como el inventor del arte nuevo. Esta introducción de un arte plumario revela su disposición. Aparentemente, 
el misionero tenía solamente conocimientos superficiales y opiniones anticipadas acerca de este arte, los indígenas y sus culturas. Asimismo, esta manera de proceder atestigua un encuentro menos cooperativo. Ignorando las tradiciones locales, introduciendo un nuevo arte plumario y tomando posesión de la función del artista de plumas, el clérigo modificó esta comunicación simbólica en gran escala, porque objetos plumarios desarrollan su amplio significado a causa de su totalidad, por medio de la combinación del material empleado, de la técnica usada y de las formas. Además, todas las actuaciones y todos los protagonistas influyen en la atribución trascendental, e incluso forman parte de esta. En este escenario todos estos aspectos esenciales del arte plumario eran modificados de una manera radical. En consecuencia, estos mosaicos documentan un cambio cultural, que se basa en desplazamientos e interrupciones y menos en comunicación e intercambio, así que este arte plumario ni pudo servir como ayuda de orientación para los neófitos indígenas en el nuevo sistema ni refleja una comunicación continuada de los indígenas por medio de imágenes de plumas.

\section{Conclusión}

En los mosaicos plumarios del Museo de América y del Museo Nacional de Colombia se ven plasmados encuentros culturales entre indígenas y europeos en Sudamérica en la época colonial de manera amplia. Representan una fuente especial para el estudio etnohistórico, porque las piezas aclaran interacciones visuales e interpersonales a varios niveles, reflexionando sobre todo los procesos desde la inspiración hasta la contemplación. Además, en comparación con fuentes escritas de la época colonial los objetos ofrecen un acceso particular a la historia colonial. Las interacciones, las influencias de ambos grupos de participantes son perceptibles directamente. En consecuencia, las obras documentan varias perspectivas acerca de estos momentos históricos de encuentros.

Los problemas de la cultura visual aducen información importante para la interpretación y contextualización de estos mosaicos, porque se consideran todas las características de los objetos -el material usado, la técnica empleada y la iconografíaIgualmente, se reflexiona respecto de las filiaciones culturales y además concerniente a las relaciones entre los objetos y las personas participantes, por consiguiente los protagonistas y las actuaciones llegan como criterios del estudio al centro de la atención. De este modo, se desarrolla una idea compleja de la situación contextual. Debido a la concentración en las interacciones entre las imágenes y los protagonistas se aclara una diversificación de la comunicación por medio de las imágenes plumarias, porque las categorías de interés -las formas de comunicación, los portadores de información y los roles de los protagonistas- son variables. Por tanto, las obras revelan particularidades diversas de actos visuales/ comunicativos.

Esta complejidad aumenta aún por otro aspecto importante, examinado por la cultura visual: la percepción y sus ambigüedades. Esta atención no puede limitarse en la captación de los mosaicos en el momento de la contemplación -en las interacciones entre las imágenes y los espectadores-, sino tiene que abarcar la apreciación de todos los actos visuales -desde la inspiración hasta el empleo y la exhibición, incluyendo también las disposiciones diferentes de todos los protagonistas- de los iniciadores, los destinatarios idealizados, los fabricantes/ artistas de plumas y los observadores y usuarios.

A causa del contexto intercultural del origen de las hechuras es preciso ampliar aún la perspectiva de la cultura visual mediante los problemas de las investigaciones de transferencias culturales: Reflexionando relativo a los mosaicos plumarios como género transferido, es posible caracterizar las relaciones entre los partícipes y circunstanciar los procesos de cambios, continuaciones e interrupciones tanto de las interacciones interpersonales como del arte plumario. Un criterio central de las investigaciones de transferencias culturales es la acentuación de las diferencias de los sistemas de referencia de los grupos participantes, aumentando así el problema de percepciones ambiguas, ya planteado por la cultura visual.

Con esta perspectiva amplia la investigación del arte plumario de la época colonial puede dar impulsos nuevos para los estudios de actos visuales, de encuentros e intercambios interculturales y de la historia común de indígenas y europeos en Sudamérica.

\section{Agradecimientos}

Prof. Dr. Úrsula Thiemer-Sachse, Beatriz Robledo Sánz, Concepción García Sáiz, Heidi King, Ana Castaño Lloris, Nuria Moreu Toloba, Mercedes Amezaga Ramos, Carmen González de Candamo, Margarita Reyes, María Victoria Gálvez, Gregor Strutz, Pável Osorio Belmon. 


\section{Referencias Citadas}

Altamirano, D.F

1891 [1715] Historia de la Misión de los Mojos, editado por M.V. Ballivian. Imprenta de "El Comercio", La Paz.

Artelan Restauración S.L.

2007 Memoria Final de la Restauración de Diversos Bienes Muebles Pertenecientes al Museo de América de Madrid. Ministerio de Cultura, Madrid.

Bredekamp, $\mathrm{H}$.

2010 Theorie des Bildakts: Frankfurter Adorno-Vorlesungen 2007. Suhrkamp, Berlin.

Cobo, B.

1956 [ca. 1653] Obras, editado por F. Mateos. Ediciones Atlas, Madrid.

Diderot, D.

1754-1772 Encyclopédie, ou Dictionnaire raisonné des sciences, des arts et des métiers, par une société de gens de lettres. Mis en ordre \& publié par M. Diderot ... \& quant a la partie mathématique, par M. d'Alembert. Briasson, Geneve - Paris - Neufchastel.

Dittrich, S. y L. Dittrich.

2004 Lexikon der Tiersymbole. Tiere als Sinnbilder in der Malerei des 14. - 17. Jahrhunderts. Michal Imhof Verlag, Petersberg.

Doughty, R. W.

1975 Feather Fashions and Bird Preservation. A Study in Nature Protection. University of California Press, Berkeley.

Eder, F. J.

1888 [1791] Descripción de la Provincia de los Mojos en el Reino del Perú, Sacada de los Escritos Póstumos del P. Francisco Javier Eder, de la Compañía de Jesús, Misionero que fué Durante Quince Años Entre los Mismos Mójos, editado por Mako. Imprenta de "El siglo industrial", La Paz.

Escobar, T.

1993 La Belleza de los Otros. Arte Indígena del Paraguay. RP Ediciones, Asunción.

Fernández, J.P.

1895 [1726] Relación Historial de las Misiones de Indios Chiquitos, que están de Cargo de los Padres de la Compañía de Jesús de la Provincia del Paraguay. Librería de Victoriano Suárez, Madrid.

Furst, P.T.

1991 Crowns of power. Bird and feather symbolism in Amazonian shamanism. En The Gift of Birds. Featherwork of Native South American Peoples, editado por R.E. Reina y K.M. Kessinger, pp. 92-109. University Museum of Arqueology and Anthropology, Philadelphia.

Garcilaso de la Vega

2002 [1609] Comentarios Reales de los Incas, editado por J.L. Rivarola. Ediciones de Cultura Hispánica, AECI, Madrid.

Gerogiorgakis, S., R. Scheel y D. Schorkowitz

2011 Kulturtransfer vergleichend betrachtet. En Integration und Desintegration der Kulturen im europäischen Mittelalter, editado por M. Borgolte, J. Dücker, M. Müllerburg y B. Schneidmüller. Akademie Verlag, Berlin. (28 febrero) $h t t p: / /$ www.2.hu-berlin.de/sppedia/index.php5/Integration_und_ Desintegration:Beitrag_6/Zum_Geleit (12 noviembre 2013).

Gisbert, T., S. Arce y M. Cajías

2003 Textiles en los Andes Bolivianos. Fundación Cultural Quipus, La Paz.
Grieder T., A. Bueno Mendoza, C. E. Smith, Jr. y R. M. Malina. 1988 La Galgada, Peru. A Preceramic Culture in Transition. University of Texas Press, Austin.

Guamán Poma de Ayala, F.

2001 [1615] Nueva Crónica y Buen Gobierno (Det Kongelige Bibliotek, Kopenhagen: Gl. kgl. S. 2232, $4^{\circ}$ ), (mayo) http:// www.kb/dk/permalink/2006/poma/info/es/project/project. htm (3 septiembre 2012).

Heinz-Mohr, G.

1981 Lexikon der Symbole. Bilder und Zeichen der christlichen Kunst. Diederichs Verlag, Düsseldorf - Köln.

Hofmann, C. y B. Tradler

2003 Das Federzimmer Augusts des Starken. Verlag der Kunst, Dresden.

Kästner, K.-P.

2009 Amazonien. Indianer der Regenwälder und Savannen. Staatliche Ethnographische Sammlungen Sachsen, Dresden.

Kemp, W.

2003 Kunstwerk und Betrachter: Der rezeptionsästhetische Ansatz, En Kunstgeschichte. Eine Einführung, editado por H. Belting, H. Dilly, W. Kemp, W. Sauerländer y M. Warnke, pp. 247-266. Reimer Verlag, Berlin.

MacLean, E.

2006 The feather book of Dionisio Minaggio. En Nuevo Mundo Mundos Nuevos, Coloquio, 2006. (4 febrero). http:// nuevomundo.revues.org//index1629.html (28 augosto 2008).

Marperger, P.J.

1717 Ausführliche Beschreibung des Haar und Feder-handels und denen aus diesen beyden Materialien verfertigten Manufacturen da dann zugleich von unterschiedlichen darinn arbeitenden Handwerckern, vornemlich von denen Peruquenmachern Federschmückern Kürschnern Zeugwebern Bürstenbindern Sattlern und andern dahin gehörigen Professionen und deren recht gehandelt wird. Ingleichen auch zur Conservation und Verbesserung der Haupt-haar viel schöne Experimenta. Verlegts J.F. Braun, Leipzig.

Molina, C. de.

2008 [1575] Relación de las Fábulas y Ritos de los Incas, editado por J. Calvo Pérez y H. Urbano. Universidad de San Martín de Porres, Lima.

Murúa, M. de. 2004 [1590] Historia del Orígen y Genealogía Real de los Reyes Ingas del Pirú: de sus Hechos, Costumbres, Trajes y Manera de Gouierno Compuesta por el Padre Fray Martín de Morúa [Códice Galvin]. Testimonio, Madrid.

Museo de América. s.a. Inventario/Búsqueda General. http:// ceres.mcu.es/pages/SimpleSearch? Museo $=$ MAM $(16$ febrero 2015).

Museo Nacional de Colombia

2013 Pieza del mes. Septiembre 2006. (28 Junio). http:// www.museonacional.gov.co/colecciones/pieza-del-mes/ colecciones-pieza-del-mes-2006/Paginas/Septiembre\%20 06.aspx (16 febrero 2015).

Orellana, A. de.

1704 Relación Summaria de la Vida, y Dichosa Muerte del U. P. Cypriano Baraze de la Compañia de Iesus. Muerto á Manos de Barbaros en la Mission de los Moxos de la Provincia del Perú. Imprenta Real de Ioseph de Contreras, Lima. 
Paul, G.

2012 Visual History, Version: 2.0. Docupedia-Zeitgeschichte. (29 octubre), http://docupedia.de/zg/Visual_History_ Version_2.0_Gerhard_Paul? oldid $=85578$ (12 noviembre 2013).

Saabedra, C. de.

1965 [1620] Relación de la entrada que hizo el Gobernador D. Diego Vaca de Vega al descubrimiento y pacificación de las provincias de los indios Maynas, Cocomas y Gibaros, ... En: Relaciones Geográficas de Indias. - Perú, Tomo IV, editado por M. Jiménez de la Espada, pp. 242-256. Ediciones Atlas, Madrid.

Sachs-Hombach, K.

2003 Bildtheorien in Geschichte und Gegenwart. Ta katoptrithomena. Magazin für Theologie und Ästhetik 25. http:// www.theomag.de/25/kshl.htm (9 abril 2012).

Salinas Loyola, J. de.

1965 [1571] Descubrimientos, conquistas y poblaciones. En: Relaciones Geográficas de Indias. - Perú, Tomo IV, editado por M. Jiménez de la Espada, pp. 197-232. Ediciones Atlas, Madrid.

Sánchez Labrador, J.

1769-1776 Paraguay catholico en sus principales provincias convertidas à la Santa Fè y vassallage del Rey de España Por la predicacion de los Missioneros zelosos de la Compañía de Jesús: en gran parte arruinadas por los Mamalucos del Brasil Y restablecidas por los mismos Missioneros. Parte Segunda. Manuscrito en posesión de la Real Academia de Historia (Ms. 9/2276).

Schulz, M.

2005 Ordnungen der Bilder. Wilhelm Fink Verlag, München. Techo, N. de. 1897 [1673]. Historia de la Provincia del Paraguay de la Compañía de Jesús, editado por M. Serrano y Sanz. A. de Uribe y Compañía, Madrid - Asunción.

Yacovleff, E.

1933 Arte plumaria entre los antiguos peruanos. Revista del Museo Nacional 2:137-158, Museo Nacional de la Cultura Peruana, Lima.

\section{Notas}

1 Los números del inventario son: Museo de América: 12344 12345, 12346, 13004, 13005/13005bis, 13006, 13010, 15403, 15404, 70476; Museo Nacional de Colombia: 4-VII-5341.

2 Son los objetos con los números 12344, 12345, 13004, 13005/13005bis, 13006 y 4-VII-534.

3 Este grupo consiste en los mosaicos con los números 12346, 13010, 15403, 15404 y 70476.
La identificación del material lignificado aún no está unánime. Los restauradores de Artelan lo identifican como madera de Serjania clematidifolia Cambess de la familia de las Sapindáceas. En cambio, las restauradoras del Museo de América lo identifican como caña sin más especificaciones. La pintura visible en las fotos de detalles no es original. Probablemente fue aplicada durante una restauración de las piezas. 